NBER WORKING PAPER SERIES

\title{
A HELICOPTER TOUR OF SOME UNDERLYING ISSUES IN EMPIRICAL INDUSTRIAL ORGANIZATION
}

\author{
Ariel Pakes \\ Working Paper 27906 \\ http://www.nber.org/papers/w27906 \\ NATIONAL BUREAU OF ECONOMIC RESEARCH \\ 1050 Massachusetts Avenue \\ Cambridge, MA 02138 \\ October 2020
}

This paper focuses on the parts of Industrial Organization I know best; topics that either I or my students have worked on. I owe much of my knowledge on these topics to my students and coauthors, as well as two who taught me related material from other fields and have sadly passed away, Gary Chamberlain and Zvi Griliches. The views expressed herein are those of the author and do not necessarily reflect the views of the National Bureau of Economic Research.

NBER working papers are circulated for discussion and comment purposes. They have not been peer-reviewed or been subject to the review by the NBER Board of Directors that accompanies official NBER publications.

(C) 2020 by Ariel Pakes. All rights reserved. Short sections of text, not to exceed two paragraphs, may be quoted without explicit permission provided that full credit, including () notice, is given to the source. 
A Helicopter Tour of Some Underlying Issues In Empirical Industrial Organization Ariel Pakes

NBER Working Paper No. 27906

October 2020

JEL No. D4,L0,L1,L3

\begin{abstract}
$\underline{\text { ABSTRACT }}$
The paper considers conceptual issues underlying empirical work on markets. It has three parts. The first reviews the analysis of demand and equilibrium in retail markets and then considers recent advances in the analysis of markets which require different assumptions; markets where adverse selection and moral hazard may be important, vertical markets with bargaining, and markets wherein a centralized allocation mechanism replaces prices. The second part considers the analysis of cost and production. It reviews the simultaneity and selection issues in production function estimation and then considers; the distinction between revenue and quantity generating functions and its implications for the analysis of markups, and the empirical analysis of fixed costs and its implications for the analysis of product repositioning. The paper concludes by considering issues that arise due to the complexity of empirical analysis of market dynamics and appropriate ways of dealing with them.
\end{abstract}

\author{
Ariel Pakes \\ Department of Economics \\ Harvard University \\ Littauer Room 117 \\ Cambridge, MA 02138 \\ and NBER \\ apakes@fas.harvard.edu
}


Industrial organization is the study of market responses to environmental and/or policy change. It recognizes that very few, if any, markets are either monopolies (with one firm supplying a product that does not have competitors) or perfectly competitive (where firms have no ability to influence price). Rather virtually all markets are imperfectly competitive; markets where each firm knows its actions affect the payoffs, and hence the actions, of its competitors.

In the 1980's theorists took up the challenge of analyzing responses to environmental and policy changes in markets where each firms' actions affected all firms outcomes, and this lead to a revolution in the way markets were analyzed. The work was based on notions of Nash equilibria (1956); or "rest points" where each agent (say firm or regulator) was doing the best it could given the actions of the other agents. At an equilibrium no agent has an incentive to change its behavior and in markets not in equilibrium at least one agent does have an incentive to change. So it was natural to analyze changes in terms of the equilibria they could generate. Of course this misses the process which brings the market to equilibria, a topic I return to below.

The applied theory that followed focused on simple models where different assumptions were used to generate an understanding of what could happen in imperfectly competitive markets. Though insightful, the different assumptions (on functional forms, the timing of decisions, ...) led to different conclusions, and it was not clear which assumptions were appropriate for any given situation. The empirical work that followed tried to build frameworks that let the data tie down the needed assumptions ${ }^{2}$.

What I will try to do here is provide an overview of the issues that we have a pretty good handle on, point out areas which are just developing, and mention some of the more glaring pieces we are still missing. When considering these points, keep in mind that the question is not whether our models are "correct" in any absolute sense of the word. For either policy, or for understanding historical events, the analysis should be judged by whether it improves upon the alternatives available to the decision maker (or historian). Similarly methodological contributions should be judged in terms of their potential for enabling us to improve our analytical abilities.

In the interests of making the paper readable to a wide audience, I have not made any attempt to be exhaustive. The paper focuses on a set of conceptual issues that had to be solved in order to make the transition from theory to empirical work and mentions how they relate to issues of policy interest. Empirical examples are used to illustrate why the tools are needed and/or how they work.

An outline of the paper. The paper has three sections. The first two sections deal with what is traditionally called static analysis; competition between a fixed set of products with known cost functions. A typical question analyzed in static analysis is how will prices or productivity change in response to a change in market conditions (a merger, a tariff or other tax, or a regulatory change). Dynamics considers the implications of current actions, typically prices or investments (in physical and intangible assets, or in product development), on future profit opportunities.

I begin with a brief review of the empirical analysis of demand and equilibrium in retail markets in which costs are only a function of the quantity purchased. I then go on to focus on progress that has been made in empirically analyzing markets in which these assumptions are inappropriate and, as a result, would not enable us to analyze relevant policy issues. This includes markets where adverse selection and moral hazard may be important, vertical markets where bargaining can replace unilateral price setting, and markets where there is a centralized allocation mechanism which does not involve prices. The second part of the paper considers cost and production function analysis. It begins with a brief overview of the simultaneity and selection issues in production function estimation. I then consider the distinction between revenue and quantity generating functions and the implications of this distinction for the empirical analysis of markups using production data. This section closes with progress that has been made in the empirical analysis of fixed costs and its implications for the analysis of product repositioning.

\footnotetext{
${ }^{2}$ There were earlier attempts by exceptional authors to merge empirical work with theory for some of the primitives of economic models (e.g.'s Marschak and Andrews, 1944, Houthakker, 1955, and Gorman, 1956). However their insights were difficult to implement in a general way and generality was needed to enable the data to determine the appropriate assumptions. The computer revolution and the data, econometric techniques, and computational abilities that accompanied it, changed that.
} 
The third section of the paper deals with dynamics. My discussion of dynamics will deal solely with what I view is the basic problem hampering empirical work on dynamics and recently developed ways of circumventing it. A more complete review of dynamics is provided in another paper in this volume.

\section{Static Analysis of Demand and Equilibrium.}

The most common form of static analysis has firms choosing prices. The assumption that makes the analysis static is that the choices of price today does not have an independent effect on future profit opportunities. This rules out many markets ${ }^{3}$, but the tools of static analysis are required to analyze markets where prices have dynamic effects, and they are easier to understand in isolation. Static analysis has three components.

1. A demand function which determines the quantities of the products marketed purchased at various prices.

2. A cost function which determines how much it cost to produce those products.

3. A behavioral assumption which determines how firms set prices ${ }^{4}$.

Given these three components, the static framework is able to analyze the impact of counterfactual changes in policy or the environment on prices, profits, and, if the demand system is based on integrating individual demands, on the distribution of consumer surplus.

Demand Functions. Early work on market demand was largely in "product space". This consisted of estimating demand for each product as a function of its price and the prices of competing products. This had two problems in our context. First if there were $J$ competing products even a linear system would require on the order of $J^{2}$ coefficients and with markets with fifty or more products this was simply too many parameters to estimate with any precision. Second a demand system estimated in this way could not predict demand for new product introductions, and this was necessary in order to predict changes in the products likely to be marketed in response to environmental changes.

Our solution to these problems was to move to an analysis in "characteristic space". A product was defined by its characteristics and individual preferences over products were determined by the interaction of product characteristics with household attributes (large families could prefer large cars, poor families could be more sensitive to price, etc.). The empirical analysis estimated the importance of these interactions; see Berry, Levinsohn and Pakes $(1995,2004)$ or BLP ${ }^{5}$. The number of parameters that needed to be estimated depended only on the joint distribution of the interaction terms over households. This did not depend on the number of products marketed. Moreover, at least in principal, we could predict demand for a product given prices before it was marketed. Of course we will not do as well predicting preferences for new products whose characteristics are quite different from those in our data (e.g. lie outside of the convex hull of the characteristics in our data).

The movement to characteristic space generated two computational problems. To aggregate to market demand we had to sum up over the demands induced by the preferences of many households. Market demand was needed both to determine prices and, when household level demands were not available, to estimate the interactions needed for the demand system from a combination of market level data on quantities prices and product characteristics with publicly available data on the distribution of consumer attributes. Advances in computational abilities and the accompanying development

\footnotetext{
${ }^{3}$ Static analysis ignores the impact of current prices (or quantities); on future demand (as would occur in markets for durable, experience, or network goods), future costs (as in learning by doing, or input adjustment costs), \&/or on future equilibrium conditions (due to collusive incentives or signaling in models with asymmetric information).

${ }^{4}$ Given the demand function, prices determine quantities purchased. An alternative has firms setting quantities with prices adjusting so that those quantities are bought.

${ }^{5}$ The earliest I.O. paper in this vein was Bresnahan (1987), who used a single "quality" dimension to distinguish between automobiles in a telling analysis of collusive periods in the auto industry.
} 
of simulation techniques to approximate sums essentially solved this problem ${ }^{6}$. Second at least for consumer goods, there are often too many potential characteristics to use. Our solution was to allow for an "unobserved" characteristic which picked up the effect of the residual characteristics that we did not condition on. Since firms priced on all their characteristics we had to allow for a correlation between price and the unobservable. This is the analogue of the "simultaneity" problem in product space demand models, but here the unobservable was inside a complicated non-linear aggregate. BLP introduced a contraction mapping that allowed the researcher to express the unobservable characteristics as a linear function of observables. This enabled us to use standard instrumental variable techniques to account for correlation between the unobserved and observed characteristics.

There have been a number of improvements to and extensions of the analysis of characteristic based models which I will not review here ${ }^{7}$. I would rather conclude by pointing out two related limitations of the framework. There are active research programs trying to accommodate each, but no commonly accepted way to integrate solutions into the analysis. First the basic framework assumes that the researcher knows the products that are in the agents' choice set, and that households know the characteristics of those products. Second the framework has difficulty distinguishing between correlations in tastes and causal factors that lead to similar actions. For example is the fact that individuals in a network make similar choices a result of similarity in tastes that our observables do not control for, or is it driven by the way information flows? Similarly does the fact that individuals make similar choices over time result from some form of "switching costs" or from unobserved characteristics that we do not control for? Both appropriate policy and modeling choices often depends on these distinctions.

The demand framework outlined above is now part of the toolkit of most Industrial Organization economists, has spread rapidly to other fields of economics (public finance, health and environmental economics, market design ...) and consultancies, and has provided useful insights for both regulatory agencies (particularly in their analysis of merger activity) and data gathering agencies ${ }^{8}$.

Demand and Pricing in Retail Markets. How have we done with our demand and equilibrium assumptions in retail markets? In any given market this is easily checked. If we rely on our demand system and our equilibrium assumption then price should equal cost plus a markup. The markup can be obtained separately from the estimates of the demand system and should have a coefficient of one in the pricing equation. We also need a marginal cost function, but provided we are willing to specify marginal cost as a function of product characteristics and the prices of inputs (e.g. wages for labor) the pricing equation can estimate marginal costs. The markup depends on the demand and the cost disturbances and so must be instrumented when estimating the pricing equation ${ }^{9}$.

Pakes (2017) used the demand system for trucks Tom Wollman estimated (Wollmann AER, 2018 ) to do that analysis. The results are reviewed in table 1 below. The $R^{2}$ is a measure of the fraction of the variance in price explained by the model; it is remarkably high (as good as I have seen for a choice variable in the social sciences) and the coefficient of the markup is well within a standard error of one. We also considered changes in price over time. The only explanatory variable that exhibits noticeable changes over time for a given product is the markup as input price movements are negligible. I.e. changes in the prices of the products studied are almost solely responses to changes in the set of competing products. Changes in the markup picked up fifty to sixty percent of the variance in product prices over time. Though this is also an unusually large number for analyzing "within" changes in a choice variable in social science settings, it shows that we do less well in analyzing changes in prices

\footnotetext{
${ }^{6}$ The use of simulation to approximate integrals in economics dates at least to McFadden et. al. (1979), who used it for prediction, and Pakes, (1986) who embodied simulation techniques in an estimation algorithm. The econometric problems that arose in using these techniques were first analyzed in Mcfadden (1989) and Pakes and Pollard (1989).

${ }^{7}$ These include, but are not limited to; the use of alternative instruments (Berry et. al., 1999, Reynaert and Verboven, 2012), improved computational procedures (Dube et. al. 2012), allowing for errors in the "independent" variables (Ho and Pakes, 2014), and a deeper analysis of the model's identification properties (Berry and Haile, 2014 and 2016 ).

${ }^{8}$ For example my work with the BLS used the framework to develop ways of alleviating biases in the consumer price index; see Pakes (2003), and Erickson and Pakes, (2011).

${ }^{9}$ This, and the remainder of this paper, ignores more complicated pricing schemes such as two part tariffs and other mechanisms that lead to price discrimination. A review of the empirical analysis of these mechanisms would be a paper unto itself.
} 
Table 1: Wollmann \& Pricing Equilibrium.

\begin{tabular}{||l|cc||cc||}
\hline \hline & Price & (S.E.) & Price & (S.E.) \\
\hline \hline Gross Weight & .36 & $(0.01)$ & .36 & $(.003)$ \\
Cab-over & .13 & $(0.01)$ & .13 & $(0.01)$ \\
Compact front & -.19 & $(0.04)$ & -0.21 & $(0.03)$ \\
long cab & -.01 & $(0.04)$ & -0.03 & $(0.03)$ \\
Wage & .08 & $(.003)$ & 0.08 & $(.003)$ \\
Mârkup & .92 & $(0.31)$ & 1.12 & $(0.22)$ \\
\hline Time dummies? & No & n.r. & Yes & n.r. \\
\hline $\mathrm{R}^{2}$ & 0.86 & n.r. & 0.94 & n.r. \\
\hline \hline
\end{tabular}

Note. There are 1,777 observations; 16 firms over the period 1992-2012. S.E. $=$ Standard error.

over time than analyzing the differences across products at a given point in time, an issue I turn to now.

The use of equilibrium assumptions. Conditional on the characteristics of the goods marketed, their cost functions, and the behavioral assumption setting price, the demand and pricing framework above enables one to solve for the change in prices, profits, and the distribution of consumer welfare in retail markets. This generates an ability to analyze the impact of counterfactuals on these same variables. The rest of this section comments on extensions that generate the same capabilities in markets where the assumptions underlying the retail analysis are inappropriate. However before doing so I want to note a feature of the equilibrium analysis that we have not adequately dealt with and arises in all settings.

Nobody believes that markets react to an environmental change by instantaneously moving to a rest point. Unfortunately we know very little about the adjustment process. An appropriate adjustment model would enable us to investigate "transition dynamics". However the need for a model of adjustment is deeper than that. Since models of markets have interacting agents they generate the possibility of multiple equilibria; multiple sets of actions wherein each agent is doing the best it can given the actions of other agents. Multiplicity becomes a near certainty when we allow for the more complex models that endogenize the choice of products to be marketed (see sections 2.1 and 3).

Though we may be able to let the data determine which equilibria were played in the past, the multiplicity issue must be addressed to analyze counterfactuals, and it is our ability to analyze counterfactuals that enables us to predict the outcomes from policy altenatives. An accurate empirical model of how firms learn to adapt to change would be one way of choosing among alternative equilibria. Theorist have written extensively on learning (see Fudenberg and Levine,1998, and Hart and Mas-Colell, 2013), but there has been less empirical work. A start on the empirical analysis of adjustment in markets was made in Doraszelski, Lewis and Pakes (2018). They find support for simple learning models in situations where firms have been interacting for some time. They also note, however, that when major changes occur firms seem to experiment and we lack a framework for analyzing experimentation in environments with interacting agents.

\subsection{Extensions of the Static Framework}

There has been a significant amount of work extending the analysis to account for additional features that are central to policy. I turn to these before coming back to a deeper look at the analysis of costs 
and productivity.

Asymmetric Information, Adverse Selection and Moral Hazard. Implicit in the analysis above was the assumption that the cost of supplying the marketed product was not a function either of; who purchased the product, or of details of the contract enabling the sale. However different purchasers of health (or car) insurance have different probabilities of illness (or accidents) and will cost the insurer different amounts. Similarly loans to different people (or firms) have different default rates. In these markets actions by the purchaser after the purchase can cause costs that are not internalized by the purchaser but rather are allocated to the service provider, generating the problem of "moral hazard". In addition if the service provider does not price all the purchaser's characteristics that determine costs "adverse selection" can occur. A limited ability to price cost characteristics can result from the provider not observing those characteristics or because regulations prohibit pricing on them. I illustrate issues that these phenomena generate with examples from health insurance markets.

Adverse selection obtains its name from the fact that if insurance is offered at a higher price those who continue to purchase it will be disproportionately sick, since insurance is more valuable to them (for a simple exposition see Einav, Finkelstein, and Cullen, 2010) . In the extreme adverse selection can cause market unraveling (Ackerlof, 1970); price increases that lead to cost increases that lead to price increases, ... and eventual market disappearance. Even if the market does exist the fact that cost becomes a function of price generates computational issues as equilibrium prices must now account for the change in costs induced by price changes, and can imply that the Nash in prices equilibrium described above might not exist (the analysis of the ACA exchanges in Handel et al. 2015, considers alternatives).

There are at least two ways in which moral hazard effects the health insurance market. First the fact that health insurers pick up most of the costs of consumers accessing health services both generates incentives for consumers to access services when benefits are less than costs, and dampens incentives for individuals to take actions which improve their health. Second since the costs of the treatments health care providers prescribe are also mostly paid by an insurer, there is a moral hazard problem in prescribing. Because the relationship between symptoms and diseases is uncertain and the provider can be blamed for mistaken diagnosis moral hazard is potentially important here, and there is general agreement that doctors' choices have large impacts on healthcare costs. Recent empirical work has attempted to evaluate how different reimbursement mechanisms mitigate the resulting moral hazard problems.

Early empirical work evaluated the impact of co-pays, co-insurance, and out of pocket maxes on consumer behavior (see Cutler, McClellan, and Newhouse, 2000). More recent work has investigated various impacts of provider reimbursement mechanisms on the choice among treatment options. The worry that fee for service contracts with providers might induce over-provision has lead to research on the effect of payment mechanisms that are based on ex-ante patient risk ("capitation"), or on a categorization of illnesses ("bundled payments"). The question was whether providing monetary incentives to providers would induce skimping on care. The early results were encouraging. For example Ho and Pakes' (2014) study of women giving birth finds that capitation causes doctors to allocate to less convenient hospitals, but does not cause a decrease in the quality of care. On the other hand Einav et al. (2018) and Eliason et. al. (2018) both show that the incentives leading to the growth of long term care facilities has not increased the quality of care. So different institutional details generate different outcomes, and there is a need for detailed research.

This research needs to keep in mind that the objective of health care policy is different than that most frequently used in economics (the maximization of consumer, or consumer plus producer, surplus). Our society is "contractarian"; we have instituted laws that guarantee that a citizen who fulfills society's duties has a right to a minimal level of goods and services; including a minimal level of healthcare ${ }^{10}$. So we are faced with a market design issue: how do we insure a basic level of health care at minimal cost?

\footnotetext{
${ }^{10}$ As noted by Rawls (1971), one (though not the only) rational for contractarianism is that it is a rational response to the fact that we can not expect people to abide by the law if their family's existence is at stake. This also rationalizes a social safety net which includes health care.
} 
Two final points are worth noting. The contractarian argument for a minimal level of health care when applied to care for a communicable diseases (e.g. COVID-19), requires us to extend care to those who are not formally members of the society but interact with society's members. Finally in both health insurance and loan markets issues related to moral hazard and asymmetric information generate complex contracts. The complexity of these contracts has led to the establishment of public institutions to regulate them, and a need for research into preferred regulatory rules.

Vertical Markets. Many markets are "vertically" connected to other markets. In a typical vertical structure an intermediary contracts with a number of goods or service providers in an "upstream" market and then markets a bundle of contracted goods to consumers in the "downstream" market. Examples include; the cable television market where networks contract with content providers in the upstream market and then re-market a "tier" of content to consumers, the health care industry where insurers contract with health service providers and re-market access to a network of providers as a health insurance policy, and large retailers who purchase goods from competing manufacturers and re-market them in their outlets.

The difficulty in analyzing the impacts of changes in these settings is that there are often a small number of buyers and sellers in the upstream market and the allocation of profits between them is determined by bargained contracts rather than by Nash pricing. Moreover any change in one side of the market will affect conditions in the other, so a solution to the contracting game is needed to analyze any change in the retail market. Crawford and Yurukoglu (2012)'s analysis of the impact of a la carte (rather than tier) pricing of television content laid the groundwork for empirical models incorporating upstream bargaining.

In the Nash (1953) bargaining model each side's leverage is determined by the difference in what it would earn with and without the contract. The profits, i.e. the difference between the downstream firm's revenue from marketing the good and the upstream supplier's costs, are split by a rule which maximizes a product of these differences. So to calculate the split we need to calculate a counterfactual; i.e. if two firms are currently contracting we need an idea of what would happen were the contract broken. Would the firm change its other contracts, and would the change in the contract between these two firms induce changes in the contracts of its (upstream and downstream) competitors? Note that the way the profits are split will determine both; the costs of the downstream retailer and hence the price to consumers ${ }^{11}$, and investment incentives ${ }^{12}$. The appropriate solution to the problem of constructing counterfactuals is likely to depend on the institutional setting, however an example will show that some way of accounting for the vertical nature of a market is crucial when considering policy.

Regional television rights for Major League Baseball (MLB) are allocated to the teams (figure 1 has the regions), but to watch a team from out of your region you must purchase the out of market bundle (the OMB) which gives purchasers access to all games. So a New Yorker living in Florida could not watch the Yankees without purchasing the OMB. A class action law suit was brought against MLB characterizing this agreement to be a conspiracy to divide the market. The claim was that consumers would be better off if teams were allowed to market their telecasts in all regions. Figure 2 illustrates the two ways of analyzing this issue that were argued in litigation.

The first treats the market as a standard retail market. The team's costs are its telecast cost and each team markets their product in all regions, choosing each region's price to maximize their profits in that region. The league markets the OMB. This violates the institutions that govern this market. In reality the teams would have to bargain contracts with a cable or satellite network that controls consumers' access to the telecasts. The costs to these distributors would include the markup over costs that results from the bargained contracts and keeps the teams afloat. The distributor would then remarket both the individual team channels and the OMB to consumers, internalizing the fact that when

\footnotetext{
${ }^{11}$ Even if both the upstream and the downstream market are Bertrand price setting markets vertical merger activity will cause price changes due to the absence of double marginalization. For an early analysis of this see Villa-Boas, 2007, who extends the tools described above to allow for double marginalization.

${ }^{12}$ The impact of the bargaining split on investment incentives is still largely absent from detailed empirical modeling of vertical markets and is thought to be central to determining the tradeoffs between the benefits and costs of vertical merger activity (see chapter 4 of Whinston, 2006).
} 


\section{MLB Home Television Territories}

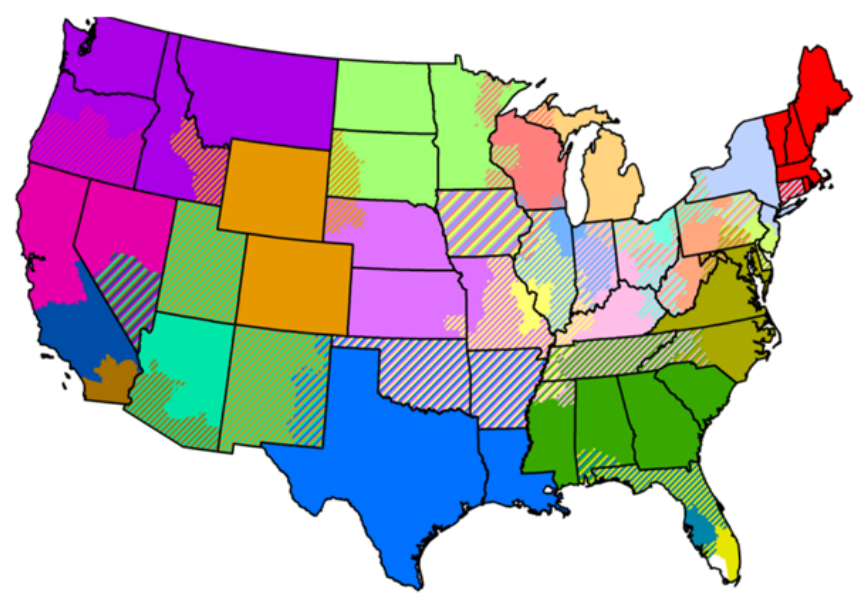

*eague defines each team's "home television territory."

In-market telecast rights are assigned to the teams.

* Out-of-market (“OOM”) telecast rights are held by the League.

OOM telecasts are sold as part of an OOM Bundle (“OMB").

Figure 1: MLB Figure 1

they increase a price of a given team some of the lost viewers would go to the OMB or to other teams. This plus the increase in cost would increase prices consumers would have to pay for either the teams' channels or the OMB bundle above what it would be were each team able to set prices individually. Moreover some of the teams would now make more money by opting out of the OMB, which would harm consumers further. That is the predictions from a standard retail market analysis were unlikely to be accurate (figure 3 summarizes), and would likely have lead to the wrong outcome.

Markets that Do Not Use Price to Allocate. In markets where prices are used allocations are determined by; tastes, the prices of the goods marketed, and endowments. However, there are many circumstances in which society (or a relevant subset like a sports league) does not want to allow monetary endowments to overly impact allocations. Examples include the allocation of; students to public schools, of kidneys to patients, of doctors to residency programs ${ }^{13}$, and the drafts of new players in professional sport leagues. To analyze the impact of environmental changes in these settings we still need a demand system and a cost or production function, but the pricing equation is replaced by an allocation rule.

The example I briefly consider is our society's notion that students should have equal opportunity to access their preferred schools (at least for the schools in the public school system). Students submit a preference ordering for schools and a centralized mechanism allocates. The analysis of a counterfactual, be it a change in the allocation rule or in the number or types of schools, would require a demand system estimated from the submitted preferences, the allocation rule, and an outcome equation which maps the student allocation and the school infrastructure into outcomes of interest.

Economists have successfully convinced many school systems to use allocation mechanisms which induce students to report their true preferences (that are "incentive compatible") and do not generate "justifiable envy" (given schools' priorities, there is not a student who would prefer another school to their assignment when a lower priority student has a place at the desired school); the leading example being the Gale Shapley (1962) deferred acceptance algorithm. The new allocation rules are generally viewed as leveling the playing field between more and less informed parents (Pathak and Sonmez, 2008).

Abdulkadiroglu et al., (2017 AER) and Agarwal and Somaini (2018, ECMA) compare the allocations

\footnotetext{
${ }^{13}$ in this case the worry was miss-aligned timing incentives, see Roth, 1984.
} 


\section{Plaintiff's Assumptions}

\section{Market Reality}

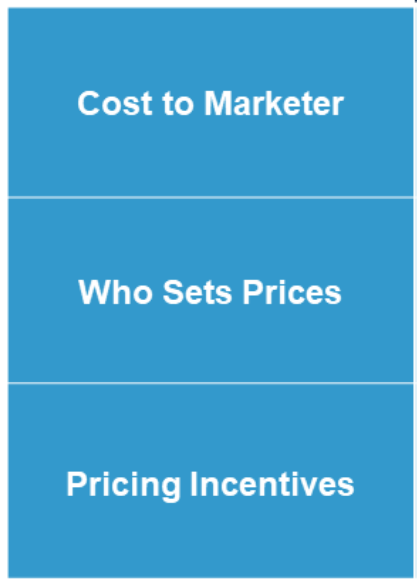

$$
\text { Cost }=\text { telecast costs }
$$

Each RSN sets the price to consumers for its own product

Each RSN sets its price independently to maximize its own revenue minus the telecast cost
RSN/MVPD negotiation sets cost

Cost $=$ telecast cost + RSN markup

MVPDs set prices to consumers for all products it markets (includes all RSN's)

An MVPD sets prices to maximize revenue from all products it markets minus the sum of their fees

Figure 2: MLB Figure 2

\section{Assumptions vs. Likely Reality}

* Plaintiff's BFW pricing assumptions.

- MVPDs face higher cost than Plaintiff assumes.

- MVPDs prices multiple products, but Plaintiff assumes RSNs set prices "independently."

Implication: Consumers face higher prices than Plaintiff assumes.

* Plaintiff did not check equilibrium conditions.

- Plaintiff assumes there still exists an OMB including all teams. However, the Yankees would make more money if they drop out and increase price.

Implication: Both Yankee and OMB consumers lose. 
that the new and old mechanisms generate. This requires estimation of the utility functions necessary to form demand systems. When the submitted preference orderings are truthful the data available for demand analysis is exceptional; BLP (2004) showed that having second, as well as first, choice data greatly improved the ability to determine differences in preferences that are not related to observables, and having a more detailed ranking is an improvement on that. To see why consider a family who has no parent at home when school is let out, and therefore wants to send the child to a school near a relative's house. The fact that the first few submitted preferences were to school's in the relative's neighborhood would allow both the algorithm and empirical work to take account of that preference even though it is not explicit in the submitted preferences ${ }^{14}$.

The demand system and the fact that there is an algorithm to calculate allocations conditional on demand generate exceptionally accurate estimates of two of the three elements needed to analyze the impact of environmental change. The missing element is a production function. To the extent that we want to analyze either the impact of the new allocation rules or how investments in the school system affect traditional measures of performance (graduation rates, subsequent wages,...) we will also need a production function, and there is a large literature in labor and public finance on teacher and funding effects on schooling outcomes on which to base that analysis.

More generally detailed empirical analysis of markets that do not use prices to allocate has, perhaps understandably, begun by focusing on direct comparisons of the allocations from different allocation rules. A next step would be to integrate an analysis of production enabling a deeper look at the outcomes those mechanisms generate.

\section{Production and Cost Functions.}

In addition to being a primitive used in the analysis of market allocations, production functions (or their "dual" cost functions ${ }^{15}$ ) are used to analyze two specific (and related) issues in empirical I.O.; the analysis of the efficiency of the distribution of output among firms, and the analysis of productivity. Productivity is the ratio of output to an index of inputs where the index is formed from estimates of production function coefficients. It is central to the analysis of the impact of infrastructure projects and other activities that might generate benefits or costs to society that are not internalized by the firms performing the activity (research and development being an important example). For reasons discussed below estimates of production functions are now also being used to enhance the analysis of markups over costs considered in section (1).

Productivity is not directly observed but rather is constructed using the production function coefficients, i.e. the parameters which determine the inputs used to produce given amounts of output. These parameters need to be estimated and estimation is complicated by the fact that payoff maximizing firms' decisions are determined, in part, by the firm's productivity. The solution, whose modern version was initiated by Olley and Pakes $(1996)^{16}$, was to model the relationship between these decisions and productivity. Olley and Pakes (henceforth OP) dealt with establishment level data and endogenized input and exit choices. In other contexts the analysis needs to account for the relationship between productivity and merger decisions, and/or the impact of productivity on the decision to privatize state owned companies.

OP analyzed the impact of the breakup of A.T.\&T on the telecommunications equipment industry. A.T.\& $\mathrm{T}$ had been a monopoly in the provision of telephone services as a result of their control over the telephone lines. A.T.\&T. purchased almost all of its equipment from its wholly owned subsidiary,

\footnotetext{
${ }^{14}$ To compare the different allocation mechanisms these papers also had to develop a framework capable of evaluating the submitted preference lists when they are strategic; that is, when truth-telling is not a dominant strategy. The analysis of demand in this context and its implications for evaluating different allocation mechanism has been extended to incorporate incorrect beliefs by Kapor et. al. who gathered survey data and integrated it with listed preferences in their study.

${ }^{15}$ Cost functions are derived by minimizing costs subject to the production function and a requirement that a given quantity of output is produced. Recent research has focused on estimating production functions rather then cost functions for several reasons; not least among them is that cost data is typically harder to access. The exception is regulated industries in which the regulator can require firms to submit costs.

${ }^{16}$ In fact the solution dates at least to Marschak and Andrews', 1944, stellar paper.
} 
Western Electric. In 1982 Judge Green split A.T.\&T. into seven regional operating companies and made it illegal for any of them to own an equipment manufacturer. This induced entry by a set of foreign producers (Ericson, Northern Telecom, Hitachi,...) and a major retrenchment in Western Electric.

Table (2) provides an indication of why it is important to account for input and entry/exit decisions when analyzing establishment level production data. The first two columns present estimates from two traditional "balanced panel" estimation algorithms; these only use the establishments that are active throughout the years covered by the panel. The within estimates assume that the productivity of a plant is constant over time. If we ignore problems induced by exit, this assumption implies that unbiased coefficient estimates can be obtained by regressing the changes in output on the changes in inputs. The total column is ordinary least squares. The third and fourth columns present the within and total estimates from a data set which keeps observations on establishments in all years they are active. The fifth column presents the estimates from using a model of input and exit decisions to control for the relationship between productivity and those decisions.

The balanced panel uses about one third of the observations available; only $40 \%$ of the establishments that were active in the initial year of the study (1972) were still active in the final year (1987), and $80 \%$ of the those active in 1987 were not active in 1972. Research is often interested in the impacts of major changes in the environment and such changes are often accompanied by a lot of entry and exit. Those who exited tended to be plants whose productivity fell as a result of the breakup, and the larger the plant the more the productivity had to fall before they exited. This induces a negative correlation between productivity and the capital of surviving firms which explains the low capital coefficients in columns (1) and (2); a finding at odds with the fact that this is a very capital intensive industry. Relatedly the firms whose productivity did grow increased their labor force causing a conflation of the impact of labor on output and the impact of productivity on labor demand, and resulting in an upward bias in the labor coefficients. The last column uses all the available data and a model of input and exit choices to correct for the "selection" and "endogeneity" problems. Compared to the within balanced panel estimates the labor coefficient falls by about $30 \%$ and the capital coefficient almost doubles. The comparison of column (5) to the simpler full sample estimates in (3) and (4) reveals a labor coefficient which is similar to the within coefficient but a capital coefficient that is much closer to the total estimates.

A "registration and certification" program which started in 1977 allowed competing firms to attach their devices to the public network provided they satisfied safety concerns. The table shows that the program was associated with an increase in the efficiency of the output allocation between 1978 and 1982. The disruption from the breakup seems to have caused a fall in both the average productivity and the efficiency of the allocation between 1982 and 1984. However the allocation improves again thereafter. OP go on to show that the productivity gains were largely a result of a reallocation of capital to more efficient establishments (see the correlation between productivity and capital in column 4); capital was miss-allocated in the regulated period. 
Alternative Estimates of Production Function Parameters ${ }^{\mathrm{a}}$

In The Telecommunications Equipment Industry.

(Standard Errors in Parentheses)

\begin{tabular}{|c|c|c|c|c|c|}
\hline \multirow[t]{2}{*}{ Sample: } & \multicolumn{2}{|c|}{ Balanced Panel } & \multicolumn{3}{|c|}{ Full Sample } \\
\hline & $(1)$ & $(2)$ & $(3)$ & (4) & $(5)$ \\
\hline $\begin{array}{l}\text { Estimation } \\
\text { Procedure }\end{array}$ & Total & Within & Total & Within & Model Based \\
\hline Labor & $\begin{array}{l}.851 \\
(.039)\end{array}$ & $\begin{array}{l}.728 \\
(.049)\end{array}$ & $\begin{array}{l}.693 \\
(.019)\end{array}$ & $\begin{array}{c}.629 \\
(.026)\end{array}$ & $\begin{array}{c}.608 \\
(.027)\end{array}$ \\
\hline Capital & $\begin{array}{l}.173 \\
(.034)\end{array}$ & $\begin{array}{c}.067 \\
(.049)\end{array}$ & $\begin{array}{c}.304 \\
(.018)\end{array}$ & $\begin{array}{l}.150 \\
(.026)\end{array}$ & $\begin{array}{c}.355 \\
(.058)\end{array}$ \\
\hline Age & $\begin{array}{c}.002 \\
(.003)\end{array}$ & $\begin{array}{l}-.006 \\
(.016)\end{array}$ & $\begin{array}{l}-.0046 \\
(.0026)\end{array}$ & $\begin{array}{l}-.008 \\
(.017)\end{array}$ & $\begin{array}{c}.010 \\
(.013)\end{array}$ \\
\hline Time & $\begin{array}{l}.024 \\
(.006)\end{array}$ & $\begin{array}{l}.042 \\
(.017)\end{array}$ & $\begin{array}{l}.016 \\
(.004)\end{array}$ & $\begin{array}{l}.026 \\
(.017)\end{array}$ & $\begin{array}{l}.020 \\
(.046)\end{array}$ \\
\hline $\begin{array}{c}\text { Other } \\
\text { Variables }\end{array}$ & - & - & - & - & $\begin{array}{l}\text { Kernel in } \\
P \text { and } h\end{array}$ \\
\hline Observations $^{\mathrm{a}}$ & 896 & 896 & 2592 & 2592 & 1758 \\
\hline
\end{tabular}

a. The dependent variable is the log of value added. Value added production function assume a constant ratio of materials per unit of output. The number of observations is smaller in column 5 because the model requires the researcher to drop the first observation on each plant.

Given the production function coefficients we can analyze the impact of the changes on the efficiency of the output allocation. Industry productivity is a share weighted average of the productivity of the plants within the industry (formally if $s_{i, t}$ is the share of output and $p_{i, t}$ is the productivity of plant $i$, then the productivity of the industry is $p_{t}=\sum_{i} s_{i, t} p_{i, t}$ ). Olley and Pakes introduce a decomposition of industry wide productivity growth into a part attributable to an increase in the average productivity of the establishments $\left(\bar{p}_{t}\right)$ and a part due to the reallocation of output across establishment $\sum s_{i, t}\left(p_{i, t}-\bar{p}_{t}\right)$. The results are in the next table. 
Decomposition of Productivity Growth ${ }^{\mathrm{a}}$

1975-87.

\begin{tabular}{ccccc}
\hline \hline Year & $p_{t}$ & $\bar{p}_{t}$ & $\sum_{i} s_{i t}\left(p_{i t}-\bar{p}_{t}\right)$ & $\rho\left(p_{i, t}, k_{i, t}\right)$ \\
\hline 1975 & 0.72 & 0.66 & 0.06 & -0.11 \\
1976 & 0.77 & 0.69 & 0.07 & -0.12 \\
1977 & 0.75 & 0.72 & 0.03 & -0.09 \\
1978 & 0.92 & 0.80 & 0.12 & -0.05 \\
1979 & 0.95 & 0.84 & 0.12 & -0.05 \\
1980 & 1.12 & 0.84 & 0.28 & -0.02 \\
1981 & 1.11 & 0.76 & 0.35 & 0.02 \\
1982 & 1.08 & 0.77 & 0.31 & -0.01 \\
1983 & 0.84 & 0.76 & 0.08 & -0.07 \\
1984 & 0.90 & 0.83 & 0.07 & -0.09 \\
1985 & 0.99 & 0.72 & 0.26 & 0.02 \\
1986 & 0.92 & 0.72 & 0.20 & 0.03 \\
1987 & 0.97 & 0.66 & 0.32 & 0.10 \\
\hline
\end{tabular}

${ }^{\mathrm{a}} \rho\left(p_{i, t}, k_{i, t}\right)$ is the correlation between estimated productivity and capital. The rest of the variables are defined in the preceding text.

Revenue versus Quantity Functions. The last table contains an anomaly. The equipment industry was an industry with rapidly advancing technology, but the table indicates no trend in average productivity. OP mention that their output measure was based on revenue, so their productivity findings should be interpreted as changes in revenue per unit of inputs rather than in output per unit of inputs. The incentives underlying the corrections discussed above are similar when we interpret their procedure as one of estimating a revenue generating function, and the determinants of revenue per unit input is of obvious importance in determining likely responses to change. However the difference between revenue and quantity generating functions becomes important when we want to distinguish between the implications of the change on quantity and price, as we often do when we want to analyze welfare. In the A.T.\&T. case a fall in prices generated by the significant increase in competition after the breakup could easily generate flat revenue productivity despite technological advances.

There have been attempts to separate out price from quantity movements using only data on revenue and expenditure on inputs (for a review with an emphasis on issues in International Trade see De Loecker and Goldberg, 2014). This would have the advantage that it does not require separate demand estimates for each market that the analysis of section (1) uses to separate markups from costs. As a result it could be done on a broad sample of industries using either publicly available data on traded firms, or data from Census Bureaus. De Loecker and Warzynski (2012) were the first to provide a set of assumptions that allowed for markup estimation from production data. They require an estimate of the output elasticity of a variable factor of production. This is not what we estimate when analyzing the relationship between revenue and total inputs in the multi-product firms that dominate the data. Still their and subsequent research developed increasingly rich ways of analyzing the relationship between inputs and revenue productivity and characterized how that relationship changed over time and across industries (see for e.g. Raval, 2018 and Demirer,2019).

To get back to markups we have to incorporate the fact that multi-product firms do not have a production function, but rather a "production possibility frontier"; i.e. for a given set of inputs different combinations of output can be produced.There have been attempts to analyze production possibility frontiers but they have been hampered by the lack of data on the separate outputs the firm produced and the inputs they used. The good news is the recent availability of disaggregated firm level output 
data (see the references in Dhyne et al. 2020). Inputs disaggregated by use are typically not available as often the same input is used in the production of several outputs (either simultaneously or fractionally with fractions unreported $)^{17}$.

A profit maximizing firm setting prices $\left(p_{1}, \ldots p_{m}\right)$ in imperfectly competitive retail markets and purchasing inputs $\left(x_{1}, \ldots x_{n}\right)$ from a competitive input market would

$$
\begin{gathered}
\max _{p_{1}, \ldots p_{m}, x_{1}, \ldots x_{n}} \sum_{j} p_{j} q_{j}\left(p_{1}, \ldots, p_{m}\right)-\sum_{i} c_{i} x_{i}, \\
\text { subject to } T\left(q_{1}, \ldots q_{m}, x_{1}, \ldots x_{n}, \omega\right) \leq 0, q \in \mathcal{R}_{+}^{m}, \& x \in \mathcal{R}_{+}^{n},
\end{gathered}
$$

where $\omega$ represents unobserved inputs (or productivity). The solution is $M+N+1$ complementary slackness conditions for the choice variables. They make it clear that even under the extreme assumptions that output markets are independent or $\sum_{j} p_{j} q_{j}\left(p_{1}, \ldots, p_{m}\right)=\Sigma_{j} p_{j} q_{j}\left(p_{j}\right)$, and the there is no jointness in production so $q_{j}=f_{j}\left(x_{j, 1}, \ldots x_{j, n}, \omega ; \theta\right)$ where $x_{j, i}$ is the allocation of input $i$ to product $j$, there does not exist a function $q_{j}=\tilde{f}_{j}\left(x_{1}, \ldots x_{n}, \omega ; \tilde{\theta}\right)$ with invariant $\tilde{\theta}$ coefficients because the allocation of $x_{i}$ among the $j$ products depends on the demand parameters. Of course demand and/or production complementarities are likely to be the reason for the existence of multi-product firms, so we need estimation procedures that apply in more than this simple case.

If we had access to the relevant demand functions we could overcome this problem. Recall however that it is the desire to estimate production parameters without having to obtain detailed demand functions that underlie the use of production data to analyze markups. The availability of disaggregate quantity and price data should enable progress in this quest as it generates two new sources of information on the relevant parameters; the first order conditions (which depend on derivatives of demand at fixed quantities), and the inequality constraints on the relationship between outputs and inputs defined by $T(\cdot)$. To obtain credible estimates from this information will require an appropriate functional form for $T(\cdot)$ (it should allow for different convexity in inputs and outputs), and attention to the same endogeneity and selection problems discussed above (the way those issues arise when using estimators based on inequalities is discussed briefly in the next subsection). These are surmountable problems so the new data sources should enable us to obtain more reliable information on markups from production data than has been possible to date.

This would facilitate the analysis of the factors underlying the observed secular fall in labor share, or equivalently the increase in returns to capital and intangibles, and its relationship to changes in markups. De Loecker, Eeckhout, and Unger (2020) investigate the trends in these returns over time, show that the observed increase is largely a result of its increase in the largest ten percent of firms, and suggest that it might be related to increases in markups. If so there remains the question of what generated the markup increase. Possible reasons range from changes in the nature of antitrust enforcement (Wollmann, 2018, notes specific rule changes, while Philippon, 2019, focuses more generally on the culture of the antitrust agencies), to an increase in the markups needed to support the fixed and sunk costs that go into the development of new goods and services. If the latter it may well be required for the large increases in consumer surplus that result from those investments which one might expect since the empirical results indicate both the prices and the quantities of the successful firms have been rising. Both possibilities require further investigation; i.e. we need an analysis of the relationship between product specific markups and antitrust activity, and a deeper understanding of how new products and processes are developed and positioned in the economy.

\subsection{Fixed Costs and Product Repositioning.}

We have not considered the estimation of fixed costs. As noted they are one rational for markups. Fixed cost estimates are also needed to analyze product repositioning. Product repositioning refers to

\footnotetext{
${ }^{17}$ Typically the input measures are expenditure weighted averages of inputs with different qualities. The implicit assumption is that the unobserved disaggregated input components are substitutable for each other at the expenditure weights. There is a question of whether this is a reasonable assumption for the data at hand. Fox and Smeets, 2011, investigate this by disaggregating labor inputs and De Loecker et. al., 2016, incorporate a correction for heterogenous inputs in their analysis of the impact of tariff reductions in India.
} 
a given set of competitors changing the characteristics of the products they market. In industries where this can be done relatively quickly, say as quickly as prices can be changed, an analysis of product repositioning is required to accurately assess the impacts of an environmental change (e.g. a merger) on prices, even in the very short run. Typically repositioning is analyzed in two stages, a stage where product characteristics are chosen followed by a stage where prices are chosen. Consistency between the stages is insured by the requirements of backward induction (or "subgame perfection") ${ }^{18}$.

A good illustration of just how quickly products can be repositioned is given in Chris Nosko's thesis (2014). He looks at the response of both Intel and its major competitor, AMD, to Intel's introduction of the Core 2 duo chip in July 2006. Figure ? shows that in the month prior to the introduction, there was intense competition for high performance chips, with AMD selling the highest priced product at just over $\$ 1000$, and seven chips selling at prices between $\$ 600$ and $\$ 1000$. Figure ? shows that in October, three months after the introduction of the Core 2 Duo, AMD no longer markets any high priced chips, there are no chips between $\$ 600$ and $\$ 1000$ marketed, and intel markets all chips priced above $\$ 1000$. Nosko goes on to explain that the returns from the research that went into the Core 2 Duo came primarily from the markups Intel was able to earn as a result of emptying out the space of middle priced chips and dominating the high priced end of the spectrum.

The product repositioning framework is relatively recent but has been used to analyze the impacts of the truck bailout in the great recession (cabs can be interchanged with trailers easily, see Wollmann 2018), the impacts of withdrawing low end computers (Eisenberg, 2014) and the cost of negotiating bilateral contracts (Ho, 2009, Crawford and Yurukoglu, 2012). In industries where repositioning is relatively easy, it should be considered by the regulatory agencies in their central role of evaluating the likely impacts of mergers on prices. Given an ability to analyze demand, prices, and profits (see section 1), that analysis would only require estimates of the fixed costs associated with introducing/withdrawing a product (or a contract), and a method of choosing among counterfactual equilibria.

The ability to estimate fixed costs relies on being able to compute counterfactual profits. That is we need to compute the profits that would have been earned were a product that was introduced was not marketed. The increment in profits from introducing the product should be expected to be greater than the fixed cost associated with the introduction conditional on the information management had at its disposal when the decision to introduce was made. Similarly if a product that could have been marketed was not, the increment in profits that could have been earned should be expected to be less than the fixed costs. So the average of these increments should provide upper and lower bounds to the average fixed costs (and a slightly more complicated algorithm could estimate these bounds conditional on measured product characteristics).

We provide a short digression on issues that arise in using bounds estimators obtained from the inequalities our models generate below, as they have appeared several times in this review. Once we have estimated the bounds on fixed costs, the remaining issue we need to consider to analyze product repositioning is specifying the counterfactual equilibrium. Though multiple equilibria is not generally thought to be a problem when analyzing prices, it is typically unavoidable when analyzing repositioning, since where one agent places its products has a discontinuous effect on the profitability of the placements of its competitors. The counterfactuals analyzed in applied work have used learning algorithms (Wollmann, 2018) or enumeration of outcomes that seem plausible (Eisenberg, 2014). Both of these are reasonable ways of addressing the problem, but as noted in section (1) and discussed further below, more empirical work on equilibrium selection is needed.

\footnotetext{
${ }^{18}$ In a formal discrete time model product repositioning can only be analyzed in this way if the characteristics chosen in the current period do not impact the profits earned from the products that might be chosen in future periods. When the cost of changing characteristics is small, empirical models often ignore the impacts of repositioning on future profits. Two-period models have also been used in empirical work that analyzes choices where longer term considerations are clearly central; the leading example being two-period entry models. The classic two-period empirical entry models assume there was no history before the initial period and there will be no future after the second. As a result it should be viewed as a reduced form which organizes historical data in telling ways; their relationship to dynamic models is clarified in Pakes (2014). This limits the usefulness of two-period models for counterfactual analysis, but at least until the recent developments in dynamic modeling, there were few other tools available for analyzing entry and exit.
} 


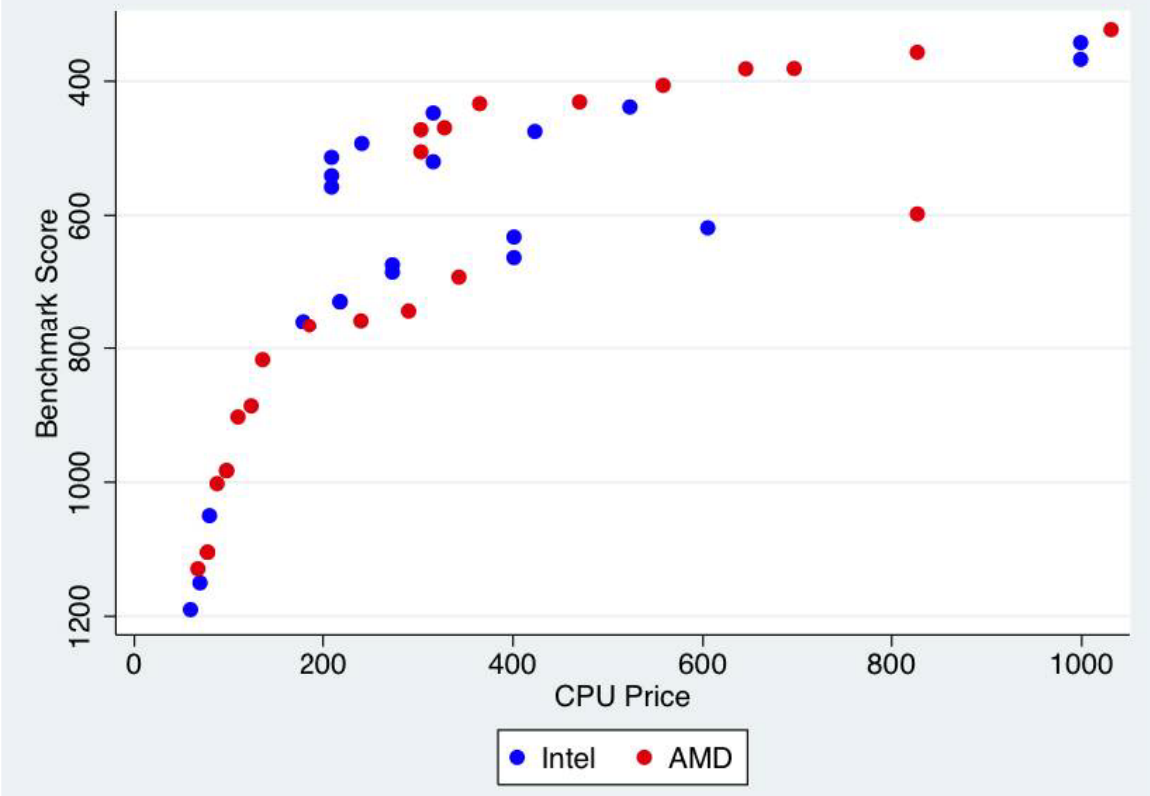

Price/Performance - June 2006

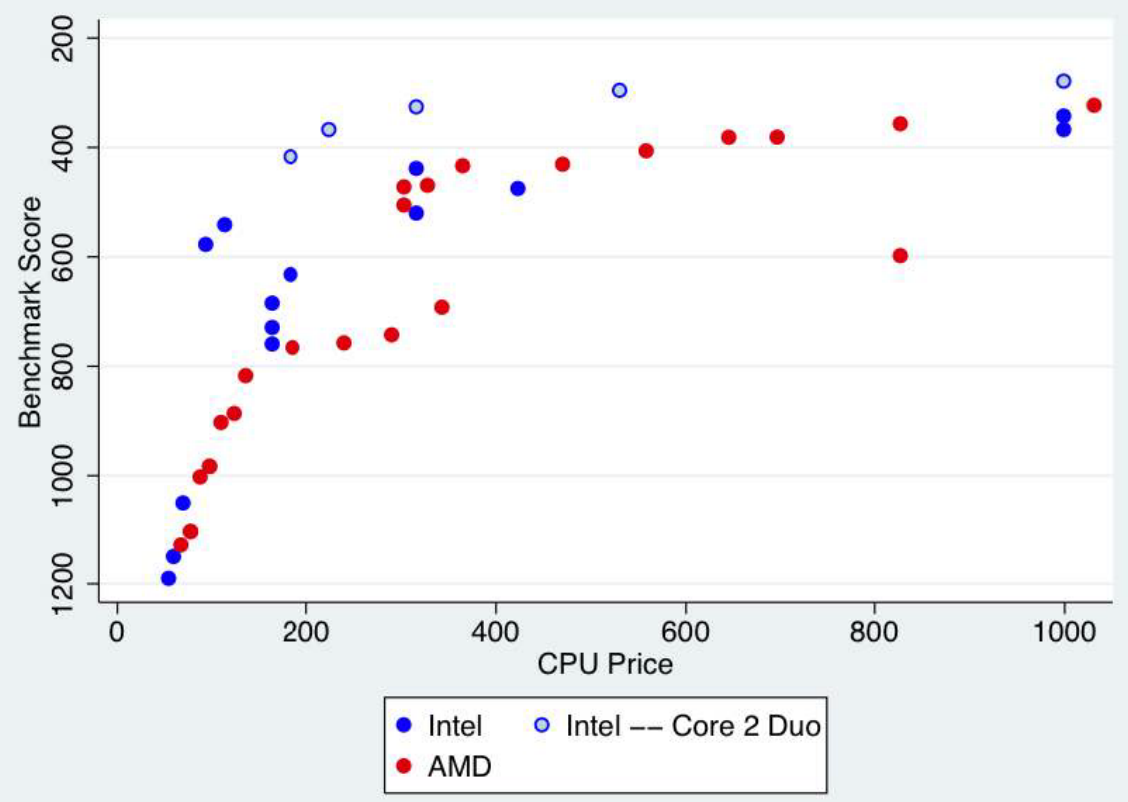

Price/Performance - July 2006

Figure 4: Nosko - Figure 4 


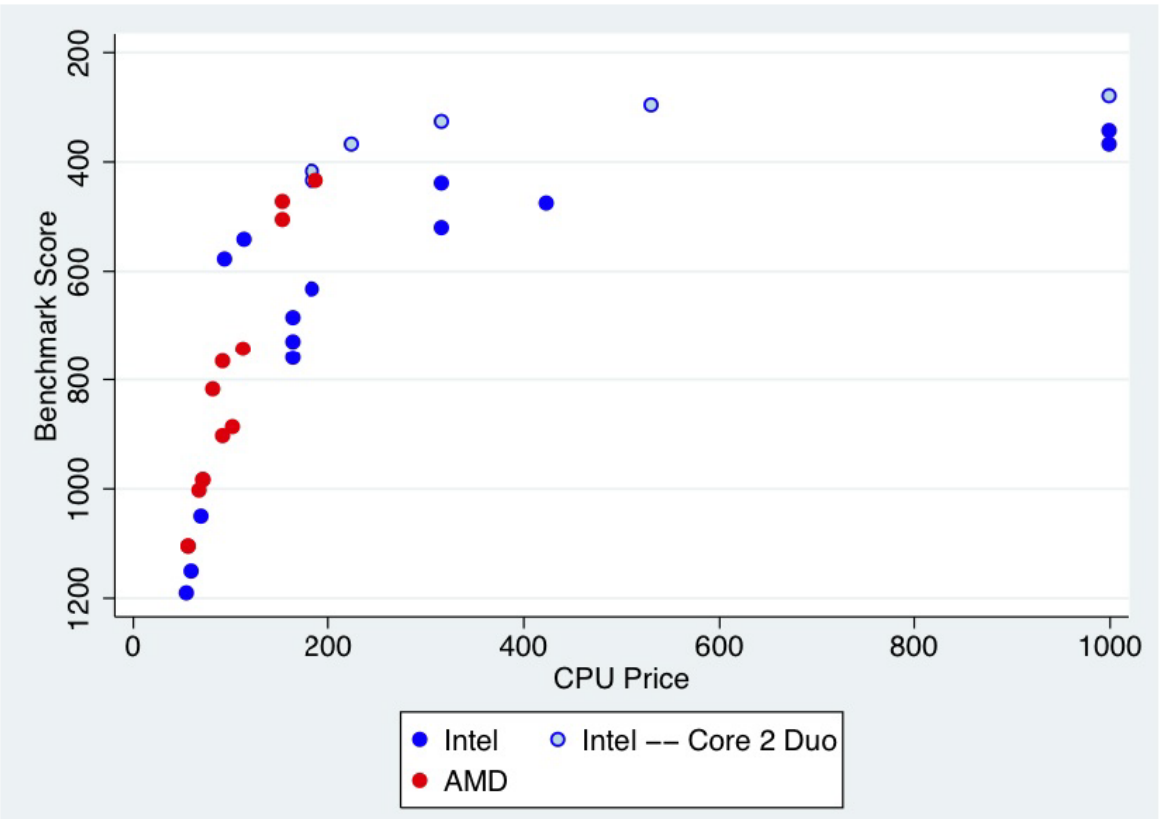

Price/Performance - Oct 2006

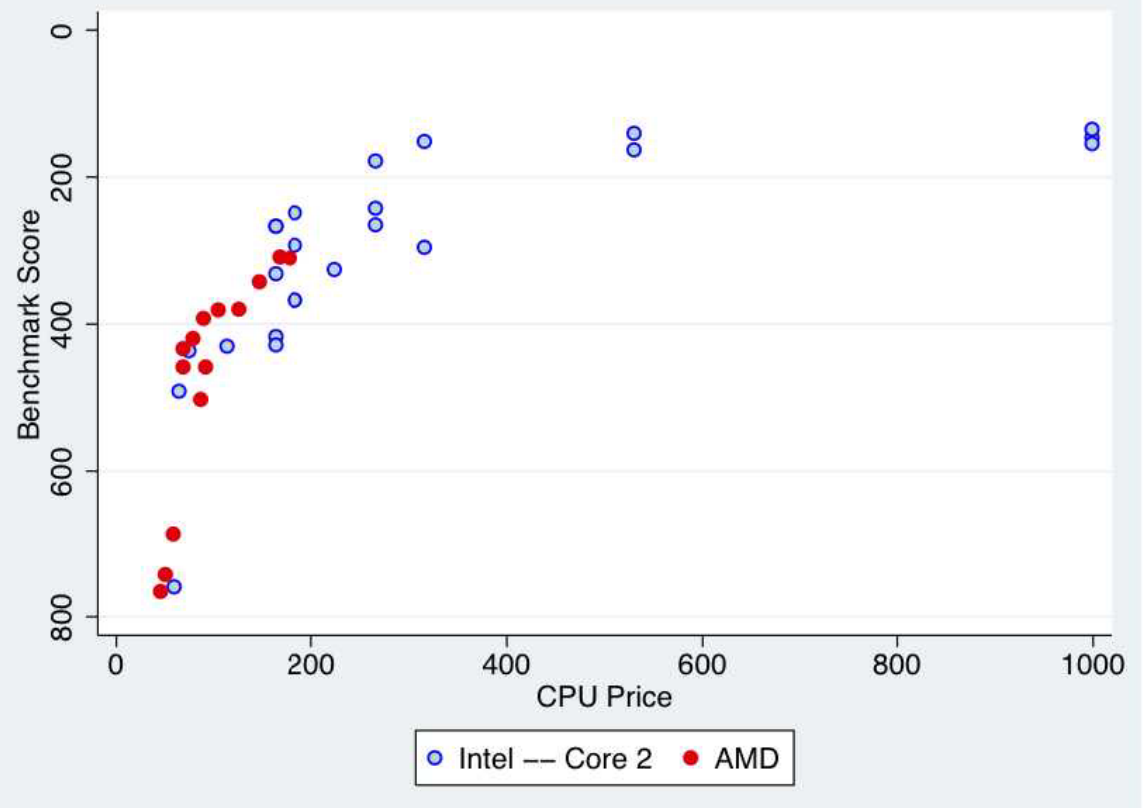

Price/Performance - January 2008

Figure 5: Nosko - Figure 5 
A digression on bounds estimators obtained from inequalities. The use of bounds in modern empirical analysis dates at least to the work of Manski (see his 2003 book), and the econometric literature on the properties of the inequality estimators that underlie them to Imbens and Manski (2004) and Chernozhukov et al.(2007). They raise two issues in the context of the models referred to here.

First the map from the parameters of a choice model to the inequalities it implies depends on the properties of the disturbances. Pakes et al. (2012) provide conditions on agents' information sets and properties of the data which clarify the implications of different modeling assumptions ${ }^{19}$. If the determinants of the disturbance were known to the agents when their choice was made a selection correction will be required, whereas if the disturbances are primarily caused by (classical) measurement and/or expectational error the inequality implied by a model without any corrections will reveal the bounds of interest. In this context a useful distinction is between empirical models that that seek to explain a measure of the profits resulting from the decision (say $\pi(\cdot)$ ), and models that seek to explain the decision per se $(d)$. Models based on measures of $\pi(\cdot)$ are likely to contain significant measurement and expectational error, while the disturbances in models of $d$ that do not have extremely detailed data on its determinants are likely to contain variables that effect the decision that the researcher does not have access to (of course both types of errors could exist in both types of models).

A second concern is how to obtain the distributions of estimators generated by inequalities. The estimators will typically be obtained by minimizing a metric in the negative parts of a set of inequalities (the square of the negative parts, or the minimum of the negative parts) since what theory tells us is that a parameter value which leads to negative values for the inequalities can not be the true parameter value. If, when we evaluate the objective function at a particular value of the parameter vector, all the inequalities are satisfied we accept that parameter. We reject the parameter if the value of the objective it generates is significantly negative. This will generate a set of acceptable values; in the linear case a polyhedron, whose vertices will determine bounds for each parameter.

We would like to know the distribution of these bounds, but this is complicated by the fact that with the sample sizes currently in use an adequate approximation to the objective function being minimized can not be obtained by assuming it is differentiable. This because when there are many inequalities different inequalities will bind with different random draws of the data, so the distribution of the bounds can not rely on the expansions used in differentiable econometric models. As a result the distribution of the estimated bounds will not be well approximated by normals, and will need to to be simulated. However modern computers and recent computational suggestions make this feasible (for a review of this literature see Canay and Shaikh, 2017). Indeed for cases which are linear in parameters, the computational burden is trivial.

\section{Dynamics.}

The applied work on dynamics started in a manner analogous to the way we started empirical work on static models. We took the Markov Perfect paradigm used by our theory colleagues, in particular Maskin and Tirole (1987a and b) who showed how it could be used to understand I.O. phenomena in simple settings, and provided a framework which had the ability to incorporate the details that seemed essential to understanding individual markets (see Ericson and Pakes, 1995). That framework made assumptions that insured that; (i) the state variables that determined agents' choice of controls evolved as a Markov process, and (ii) the equilibrium was some form of Markov perfection (i.e. controls are chosen so that no agent has an incentive to deviate given their perceptions of profit opportunities, and those perceptions are consistent with the actions of their competitors and exogenous events).

The framework generates a Markov process on the underlying states of the system. So provided the number of those states is finite, the state of a system will in finite time wander into a recurrent class of states, and once in that class will stay within it forever. The recurrent class consists of a subset of the states that the economics of the problem imply can be visited repeatedly; other states are transient, they may be visited while approaching the recurrent class, but the market can not support them in any

\footnotetext{
${ }^{19}$ Pakes, 2010, expands on these issues, but was written after the 2012 paper.
} 
lasting way.

The framework led to computational explorations of theoretical issues which were difficult to study analytically, but only a limited amount of empirical work ${ }^{20}$. The basic problem was that once the researcher included the variables that seemed important determinants of profits because of their competitive impact on demand, supply, and/or investment conditions, the twin assumptions of Markov perfection and full information (more precisely that the only unobservables were serially uncorrelated), generated a state space that was too large to be manageable. An alternative was to assume that each firm only had access to a subset of those variables and look for a Bayesian perfect equilibrium, but then the complexity of the calculations required to obtain optimal policies increased dramatically (posteriors needed to be calculated, and they had to be consistent with optimal policies).

That is once we took into account the cognitive and memory requirements for computing the policies generated by Markov perfection it was both; (i) difficult for the researcher to use them, and more importantly, (ii) it was hard to believe that these models were the best way to approximate how management made decisions. The first attempt in Industrial Organization to attack this problem was by Benkard et al. (2008) who introduced the notion of "Oblivious Equilibrium". It was introduced as a computational approximation to full information Markov perfect models, much as "mean field theory" in physics and probability approximates the behavior of high dimensional objects by simple averages. The approximation assumed that no matter the current state, the distribution of future states used in calculating continuation values was the long-run average of the probabilities of those states appearing. They show that this can greatly simplify the computation of policies and provide examples where it approximates Markov Perfect policies well ${ }^{21}$.

Fershtman and Pakes (2012) take a behavioral approach to the problem and introduce the notion of experience based equilibrium (EBE). EBE allows different firms to rely on different information sets when making their decisions. This either because of asymmetric information, or because cognitive constraints limit management's ability to associate different policies with too fine a partition of the state space. The state space that governs the evolution for the market as a whole can still be quite large, consisting of the set of information sets of the different participants. However individual decisions only depend on their own information.

The equilibrium has two requirements; (i) agents choose actions which maximizes their perceptions of their discounted returns, (ii) those perceptions are at least consistent with what the agent observes. These conditions imply that for states that are visited repeatedly, formally for those in the recurrent class, perceptions will eventually be consistent with observed outcomes, and perceived discounted values from the actions taken in those states will equal the actual expected discounted values resulting from those actions.

Fershtman and Pakes also provide an algorithm for computing equilibria. The algorithm has an interpretation as a learning algorithm; that is it shows how to use past outcomes to update the agent's perceptions of the expected discounted values from taking different choices, assuming only that the agent always chooses the action that maximizes its perceived discounted value. When the algorithm's learning process is an adequate approximation to the way management behaves, it can plot likely transitions from one environment to another. That is, it provides a transition path and selects out an equilibrium (or if the transition path is simulated repeatedly it generates a distribution of likely equilibria).

The learning process is "asynchronous"; i.e. an iteration starts at a particular state of the market and

\footnotetext{
${ }^{20}$ Computational examples include Besanko et. al. (2010 ECMA) who study learning by doing with forgetting, Fershtman and Pakes (2000 RAND) who study collusion in a dynamic game with investment and entry, and Gowrisankaran (1999 RAND) and Mermelstein et al. (2020 J.P.E), both of whom endogenize merger decisions. There had been earlier empirical work using different frameworks; for example Porter (1983) studied collusion using the influential repeated game framework in Green and Porter (1984). For an early empirical piece which uses the Ericson Pakes framework and incorporates the institutional detail that seems necessary for policy analysis see Benkard ( 2004 RESTUD). There has also been work on formulating market demand functions when consumers choices are explicitly dynamic, see Hendel and Nevo (2006) and the literature they cite. Somewhat dated reviews of dynamic empirical work on markets is available in Ackerberg et al. (2007), and of computational work is in Doraszelski and Pakes (2007).

${ }^{21}$ For more on the underlying problem, see Pakes (2016), and for extensions to the Oblivious Equilibrium concept see Ifrach and Weintraub, (2017, Restud).
} 
proceeds by moving to another state and then updating its estimates of discounted values from feasible actions from the starting state. The updating is similar to reinforcement learning; it keeps in memory an estimate of the discounted values from each possible action at each of the individual's states, simulates individual outcomes from the algorithm's current state, and then updates the initial discounted values for the particular state the algorithm is in by a weighted average of the actual simulated outcome (evaluated at the initial estimates of the discounted values) and the initial estimates. The simulated outcomes are also used to update the state of the algorithm, so the algorithm mimics reality in that it only learns from the outcomes from one state in each "period" (i.e. iteration).

EBE is similar in spirit to the theoretical literature on self-confirming equilibrium (Fudenberg and Levine, 1993). As in that literature "off the equilibrium path" behavior is unconstrained. In the Markov environment considered in EBE this implies the possibility of a different source of multiplicity than those already apparent in Markov or Bayesian perfect equilibria of dynamic games (both of which satisfy the conditions of an EBE). We classify the points in the recurrent class as interior or boundary points. At an interior point all feasible actions always result in outcomes within the recurrent class. So in equilibrium each agent's perceptions of the values generated by all possible actions are objectively correct. Boundary points have feasible (though perceived to be non-optimal) actions which take them out of the recurrent class. Beliefs about outcomes outside of the recurrent class are not constrained by the equilibrium notion, and different sets of beliefs about the value of outcomes not in the recurrent class can generate different recurrent classes. Asker et al. (forthcoming) provide a testable refinement ("boundary consistency") which restricts the equilibria by insuring that beliefs on values outside of the recurrent class are consistent with the history prior to entering the recurrent class and initial beliefs.

The computational structure of the algorithm builds on Pakes and McGuire (2001). The update of continuation values only requires adding two numbers; it does not require computing an integral over possible transitions $^{22}$. Also the algorithm wanders into a recurrent subset of all possible states and stays within it. The cardinality of that subset depends on the economics of the problem and need not increase in any particular way with the number of state variables. These two properties of the algorithm, together with a stochastic test of convergence introduced in the Fershtman Pakes article, imply that the algorithm's computational burden does not necessarily increase exponentially (or even geometrically) with the number of state variables (the algorithm does not have a "curse of dimensionality"). In our calculations the number of states in the recurrent class tends to grow linearly in the dimension of the state space, though the number of iterations before convergence can be large and ways of mitigating that burden are needed.

With appropriate choice of agents' information sets several previous empirical papers can be characterized as being based on an EBE. A recent and important example is Brancaccio et al. (2020). They endogenize transportation costs in a model of international trade of products transported by bulk shipping, and then show how various changes in the environment are likely to effect trade costs and hence trade. Boats arriving in a given location are either matched with a shipper or left to chose where to "ballast" (travel empty). The boat's decision is modeled as a dynamic program where the boat owner is assumed to only know the average value of each location over a long time period and the associated transport costs; i.e. the owners do not know the distribution of values consistent with the current state of the system. The paper solves for the "steady state" equilibrium distribution of values and transport costs under these assumptions and alternative values of the parameter vector, averages the data at the different ports over time, and estimate the values of the parameter from the observed cross-sectional distribution of boats and their movements.

In the Brancaccio et al. paper there was a fairly clear notion of what reasonable information sets might be, and they did not vary among participants. For many problems neither of these conditions will be met. Then information sets will have to be determined empirically by investigating the relationship between the controls the firm choses and available data. Moreover that analysis is likely to generate serially correlated residuals. I.e. the researcher may not have data on all the determinants of each managemer's decisions and the determinants not observed, like almost all economic variables, are likely to be serially correlated. So empirical work will likely require estimation and computation algorithms

${ }^{22}$ It uses stochastic integration; see Robbins and Monro's (1956). 
that allow for serially correlated unobservables ${ }^{23}$.

After a long hiatus methodological work on dynamics has been able to provide procedures which circumvent many of the problems that plagued earlier empirical work. The question that remains is whether these developments will lead to analogues of the rich and informative set of empirical studies that followed the developments in static models. The answer will come from empirical work which is just now (re) starting.

\section{Conclusion.}

The testimony to the accomplishment of empirical Industrial Organization, and its contribution to both policy and the understanding of historical events, is embodied in the wealth of empirical work on separate industries increasingly available. I have not tried to review those studies here, focusing instead on methodology with a few cites to early work and periodic illustrations of usefulness. However the depth of understanding that the field has been able to achieve can only be truly appreciated by accessing the individual industry studies.

My goal here was to give colleagues from other fields an overview of what empirical I.O. can currently do and the problems still facing us. To the extent that we have made progress, it was a result of serious attempts to understand the way markets work, and realizing that to embody the required detail into our models required further methodology. Often that methodology was adapted from our theory or econometric colleagues, as should be expected from a field which often combines theory with empirical work.

\section{References}

1. Abdulkadiroglu, A., N. Agarwal, and P. Pathak. 2017. "The Welfare Effects of Coordinated Assignment: Evidence from the NYC HS Match." American Economic Review 107(12): 36353689 .

2. Ackerberg D., L. Benkard, S. Berry, and A. Pakes 2007. "Econometric Tools for Analyzing Market Outcomes." In J. Heckman and E. Leamer (Eds.) The Handbook of Econometrics (pp. 4171-4276). Amsterdam: North-Holland.

3. Agarwal, N. and P. Somaini. 2018. "Demand Analysis using Strategic Reports: An Application to a School Choice Mechanism." Econometrica 86(2): 391-444.

4. Akerlof, George A. 1970. "The Market for 'Lemons': Quality Uncertainty and the Market Mechanism." Quarterly Journal of Economics 84(3): 488-500.

5. Asker, J., C. Fershtman, J. Jeon, and A. Pakes. Forthcoming. "A Computational Framework for Analyzing Dynamic Procurement Auctions: The Market Impact of Information Sharing." RAND Journal of Economics.

6. Benkard, L., 2004. "A Dynamic Analysis of the Market for Wide-Bodied Commercial Aircraft." Review of Economic Studies 71(3): 581-611.

7. Benkard, L., B. Van Roy, and G. Weintraub. 2008. "Markov Perfect Industry Dynamics with Many Firms." Econometrica 76(6): 1375-1411.

8. Berry, S., J. Levinsohn, and A. Pakes. 1995. "Automobile Prices in Market Equilibrium." Econometrica 63(4): 841-890.

9. Berry, S., J. Levinsohn, and A. Pakes. 1999. "Voluntary Export Restraints on Automobiles: Evaluating a Trade Policy." American Economic Review, 89(3): 400-430.

${ }^{23}$ The optimal way of doing so will depend on the structure of the appropriate model. Berry and Comapaini (2019) provide an early example; they estimate a full information game with serially correlated errors. 
10. Berry S., J. Levinsohn, and A. Pakes. 2004. "Estimating Differentiated Product Demand Systems from a Combination of Micro and Macro Data: The Market for New Vehicles." Journal of Political Economy 112(1): 68-105.

11. Berry, S. and P. Haile, 2014; "Identification in Differentiated Products Markets Using Market Level Data" Econometrica, 82 (5): 1749-1798.

12. Berry, S. and P. Haile. 2016. "Identification in Differentiated Product Models", Annual Review of Economics, 8: 27-52.

13. Berry, S. and G. Compiani. 2018. "An Instrumental Variables Approach to Dynamic Models." Yale working paper.

14. Besanko, D., U. Doraszelski, and Y. Kryukov. 2014. "The Economics of Predation: What Drives Pricing When There is Learning-By-Doing?" American Economic Review 104(3): 868-897.

15. Brancaccio, G., M. Kalouptsidi, and T. Papageorgiou. Forthcoming. "Geography, Transportation, and Endogenous Trade Costs. Econometria.

16. Bresnahan T. 1987. "Competition and Collusion in the American Automobile Market: The 1955 Price War." Journal of Industrial Economics XXXV(4): 457-482.

17. Canay, I.A. and A.M. Shaikh (2017): "Practical and Theoretical Advances for Inference in Partially Identified Models." In B. Honore, A. Pakes, M. Piazzesi, \& L. Samuelson (Eds.), Advances in Economics and Econometrics: Volumen 2: Eleventh World Congress, (Econometric Society Monographs, pp. 271-306). Cambridge University Press.

18. Chernozhukov, V., H. Hong, and E. Tamer. 2007. "Estimation and Inference on Parameter Sets in Econometric Models." Econometrica 75(5): 1243-1284.

19. Crawford, G. and A. Yurukoglu. 2012. "The Welfare Effects of Bundling in Multichannel Television Markets." American Economic Review 102(2): 643-85.

20. Cutler, D., M. McClellan, and J. Newhouse. 2000. "How Does Managed Care Do It?" RAND Journal of Economics 31(3): 526-548.

21. De Loecker, J., J. Eeckhout, and G. Unger. 2020. "The Rise of Market Power and the Macroeconomic Implications." The Quarterly Journal of Economics 135(2): 561-644.

22. De Loecker, J., and P. Goldberg. 2014. "Firm Performance in a Global Market." Annual Review of Economics, 6: 201-227.

23. De Loecker, J., P. Goldberg, A. Khandelwal, and N. Pavcnik. 2016. "Prices, Markups, and Trade Reform." Econometrica 84(2): 445-510.

24. De Loecker, J. and F. Warzynski. 2012. "Markups and Firm-Level Export Status." American Economic Review 102(6): 2437-2471.

25. Demirer, M. 2020. "Production Function Estimation with Factor-Augmenting Technology: An Application to Markups." MIT working paper.

26. Doraszelki, U., and A. Pakes. 2007. "A Framework for Applied Dynamic Analysis in I.O." Vol. 3, Chapter 30, 1889-1966, in The Handbook of Industrial Organization, M. Armstrong and R. Porter ed.s.

27. Doraszelski, U., G. Lewis, and A. Pakes. 2018. "Just Starting Out: Learning and Equilibrium in a New Market." American Economic Review 108(3): 565-615. 
28. Dhyne, E., A. Petrin, V. Smeets, and F. Warzynski. 2020. "Theory for Extending Single-Product Production Function Estimation to Multi-Product Settings." Aarhus University working paper.

29. Dube, J., J. Fox, and C. Su, 2012. "Improving the Numerical Performance of BLP Static and Dynamic Discrete Choice Random Coefficients Demand Estimation." Econometrica 80(5): 22312267.

30. Einav, L., A. Finkelstein, and M. Cullen. 2010. "Estimating Welfare in Insurance Markets Using Variation in Prices." Quarterly Journal of Economics 125(3): 877-921.

31. Einav, L., A. Finkelstein, and N. Mahoney. 2018. "Provider Incentives and Healthcare Costs: Evidence from Long-Term Care Hospitals." Econometrica 86(6): 2161-2219.

32. Eizenberg, A. 2014. "Upstream Innovation and Product Variety in the United States Home PC Market." Review of Economic Studies 81(3): 1003-1045.

33. Eliason, P., P. Grieco, R. McDevitt, and J. Roberts. 2018. "Strategic Patient Discharge: The Case of Long-Term Care Hospitals." Americana Economic Review 108(11): 3232-3265.

34. Ericson, R. and A. Pakes. 1995. "Markov-Perfect Industry Dynamics: A Framework for Empirical Work." Review of Economic Studies 62(1): 53-82.

35. Erickson, T. and Ariel Pakes. 2011. "An Experimental Component Index for the CPI: From Annual Computer Data to Monthly Data on Other Goods." American Economic Review 101(5): 1707-1738.

36. Fershtman, C. and A. Pakes. 2000. "A Dynamic Oligopoly with Collusion and Price Wars." RAND Journal of Economics 31(2): 207-236.

37. Fershtman, C. and A. Pakes. 2012. "Dynamic Games with Asymmetric Information: A Framework for Empirical Work." Quarterly Journal of Economics 127(4): 1611-1661.

38. Fox, J. and V. Smeets. 2011. "Does Input Quality Drive Measured Differences in Firm Productivity." International Economic Review 52(4): 961-990.

39. Fudenberg, D. and Levine, D.K. 1993. "Self Confirming Equilibrium." Econometrica 61(3): 523545.

40. Gale, D. and L.S. Shapley. 1962. "College Admissions and the Stability of Marriage." American Mathematical Monthly 69(1): 9-15.

41. Gorman, W.M. 1956 "The Demand for Related Goods: A Possible Procedure for Analysing Quality Differentials in the Egg Market." First circulated as Journal Paper No. 2319, Iowa Agricultural Experiment Station, November 1956. Reprinted in the Review of Economic Studies, 1980, 47: 843-856.

42. Gowrisankaran, G. 1999. "A Dynamic Model of Endogenous Horizontal Mergers." RAND Journal of Economics 30(1): 56-83.

43. Green, E., and R. Porter. 1984. "Noncooperative Collusion under Imperfect Price Information." Econometrica 5(1): 87-100.

44. Haile, P. and E. Tamer 2003. "Inference with an Incomplete Model of English Auctions." Journal of Political Economy 111(1): 1-51.

45. Handel, B., I. Hendel, and M. Whinston. 2015. "Equilibria in Health Exchanges: Adverse Selection vs. Reclassification Risk." Econometrica 83(4): 1261-1313. 
46. Hendel, I. and A. Nevo. 2006. "Measuring the Implications of Sales and Consumer Inventory Behavior." Econometrica 74(6): 1637-1673.

47. Ho, K. 2009. "Insurer-Provider Networks in the Medical Care Market." American Economic Review 99(1): 393-430.

48. Ho, K. and A. Pakes. 2014. "Hospital Choices, Hospital Prices, and Financial Incentives to Physicians." American Economic Review 104(12): 3841-3884.

49. Houthakker, H.S. 1955. "The Pareto Distribution and the Cobb-Douglas Production Function in Activity Analysis." The Review of Economic Studies 23(1): 27-31.

50. Ifrach, B., and G.Y. Weintraub. 2017. "A Framework for Dynamic Oligopoly in Concentrated Industries." The Review of Economic Studies 84(3): 1106-1150.

51. Imbens, G. and C. Manski. 2004. "Confidence Intervals for Partially Identified Parameters." Econometrica 72(6): 1845-1857.

52. Kapor, A., C. Neilson, and S. Zimmerman. 2020. "Heterogeneous Beliefs and School Choice Mechanisms" American Economic Review 110(5): 1274-1315.

53. Manski, C. F. 2003. Partial Identification of Probability Distributions. Springer-Verlag, New York.

54. Marschak, J. and W.H. Andrews. 1944. "Random Simultaneous Equations and the Theory of Production." Econometrica 12(3/4): 143-220.

55. Mas-Colell, A. and S. Hart, 2013. "Simple Adaptive Strategies from Regret-Matching to Uncoupled Dynamics." World Scientific Series in Economic Theory, Vol. 4.

56. Maskin, E. and Tirole, J. 1988a. "A Theory of Dynamic Oligopoly, I: Overview and Quantity Com-petition with Large Fixed Costs." Econometrica 56(3): 549-569.

57. Maskin, E. and Tirole, J. 1988b. "A Theory of Dynamic Oligopoly, II: Price Competition, Kinked Demand Curves, and Edgeworth Cycles." Econometrica 56(3): 571-599.

58. McFadden, D., F. Reid, A. Talvitie, M. Johnson, and Associates. 1979. "The Urban Travel Demand Forcasting Project," Final Report, Vol. I, Institute of Transportation Studies, University of California, Berkeley. http://emlab.berkeley.edu/wp/utdfp/vol1.pdf

59. McFadden, D. 1989. "A Method of Simulated Moments for Estimation of Discrete Response Models Without Numerical Integration." Econometrica 57(5): 995-1026.

60. Mermelstein, B., V. Nocke, M. Satterthwaite, and M. Whinston, 2020. "Internal versus External Growth in Industries with Scale Economies: A Computational Model of Optimal Merger Policy," Journal of Political Economy 128(1): 301-341.

61. Nash, J. 1951. "Non-Cooperative Games." The Annals of Mathemeatics 54(2): 286-295.

62. Nash, J. 1953. "Two-person Cooperative Games." Econometrica 21(1): 128-140.

63. Nosko C. 2014. "Competition and Quality Choice in the CPU Market." Chicago Booth working paper.

64. Olley, S. and Pakes, A. 1996. "The Dynamics of Productivity in the Telecommunications Equipment Industry." Econometrica 64(6): 1263-1298.

65. Pakes, A., 1986. "Patents as Options: Some Estimates of the Valueof Holding European Patent Stocks." Econometrica 54(4): 755-784. 
66. Pakes, A., 2003. "A Reconsideration of Hedonic Price Indexes with an Application to PC's." American Economic Review 93(5): 1578-1596. .

67. Pakes, A. 2010. "Alternative Models for Moment Inequalities." Econometrica 78(6): 1783-1822.

68. Pakes A. 2014. "Behavioral and Descriptive Forms of Choice Models." International Economic Review 55(3): 603-624.

69. Pakes A., Porter J., Ho K., and J. Ishii 2015, "Moment Inequalities and Their Application." Econometrica 83(1): 315-334.

70. Pakes A. 2016, "Methodological Issues in Analyzing Market Dynamics." In Advances in Dynamic and Evc F. Thuijsman \& F. Wagener (eds.) . Switzerland: Springer International Publishing, pp. 43-75.

71. Pakes, A., 2017. "Empirical Tools and Competition Analysis: Past Progress and Current Problems," International Journal of Industrial Organization 53: 241-266.

72. Pakes, A. and David Pollard. 1989. "Simulation and the Asymptoticsof Optimization Estimators," Econometrica 57(5): 1027-1057.

73. Pakes, A. and P. McGuire. 2001. "Stochastic Algorithms, Symmetric Markov Perfect Equilibria, and the 'Curse' of Dimensionality." Econometrica 69(5): 1261-1281.

74. Pathak, P. and T. Sonmez. 2008. "Leveling the Playing Field: Sincere and Sophisticated Players in the Boston Mechanism." American Economic Review 98(4): 1636-1652.

75. Philippon, T. 2019. "The Great Reversal: How America Gave Up on Free Markets?" The Belknap Press of Harvard University.

76. Porter, R. 1983. "A Study of Cartel Stability: The Joint Executive Committee, 1880-1886" The Bell Journal of Economics 14(2): 301-314.

77. Raval, D. 2019a. "Testing the Production Approach to Markup Estimation." FTC working paper.

78. Robbins, H., and S. Monro. 1951. "A Stochastic Approximation Technique." Annals of Mathematics and Statistics 22(3): 400-407.

79. Roth, A.E. 1984. "The Evolution of the Labor Market for Medical Interns and Residents: A Case Study in Game Theory." Journal of Political Economy 92(6): 991-1016.

80. Villas-Boas, S. B., 2007. "Vertical Relationships between Manufacturers and Retailers: Inference With Limited Data." Review of Economics Studies, 74 (2): 625-652.

81. Whinston, M., 2006. Lectures on Antitrust Economics, MIT Press. Chaper 4.

82. Wollmann, T. 2018. "Trucks without Bailouts: Equilibrium Product Characteristics for Commercial Vehicles." American Economic Review 108(6): 1364-1406.

83. Wollmann, T. Forthcoming. "Stealth Consolidation: Evidence from an Amendment to the HartScott-Rodino Act." American Economic Review: Insights. 